\title{
Clinical Characteristics of COVID-19 Infection in the Pediatric Age Group
}

\author{
Huseyin Gumus ${ }^{1 \star}$, Yasin Ozcan ${ }^{2}$, Halil Kazanasmaz ${ }^{1}$, Abit Demir ${ }^{1}$, Ahmet Guzelcicek ${ }^{1}$
}

${ }^{1}$ Faculty of Medicine, Department of Pediatrics, Harran University, Sanliurfa, TURKEY

${ }^{2}$ Medical School, Department of Ophthalmology, Yeditepe University, Istanbul, TURKEY

*Corresponding Author: huseyingumus2163@hotmail.com

Citation: Gumus H, Ozcan Y, Kazanasmaz H, Demir A, Guzelcicek A. Clinical Characteristics of COVID-19 Infection in the Pediatric Age Group. Electron J Gen Med. 2021;18(5):em308. https://doi.org/10.29333/ejgm/11019

\section{ARTICLE INFO}

Received: 8 May 2021

Accepted: 19 Jun. 2021

\begin{abstract}
Aim: To investigate the complaints and findings of COVID-19 infection in a paediatric age group.

Material and Method: The study included 130 patients with COVID-19 infection confirmed with reversetranscription polymerase chain reaction (RT-PCR) test positivity. The cases were evaluated in respect of demographic data, such as age and gender, and clinical findings, such as fever, weight, cough, shortness of breath, and history of infectious contact.

Results: Evaluation was made of 130 COVID-19-positive paediatric patients, comprising 69 (53\%) males and 61 (47\%) females, of which 54\% were asymptomatic and 5.4\% had severe clinical findings requiring follow up in the Intensive Care Unit (ICU). Of the symptomatic patients, fever was determined in $30 \%$, listlessness in $24 \%$, cough in $10.8 \%$, respiratory problems in $9.2 \%$, diarrhea in $6.2 \%$, abdominal pain in $6.2 \%$, vomiting in $2.3 \%$, joint pain in $2.3 \%$, and convulsions developed in $1.5 \%$ who had no previous history of convulsions. Of the 7 patients who required intensive care, 2 had cerebral palsy, 1 had hydrocephaly+shunt, 1 had metabolic disease (propionic acidemia), 2 had a history of trauma (struck by a motor vehicle), and in 1 there was no comorbidity. Mortality developed in 6 of the 7 patients in ICU.

Conclusion: In a significant proportion of children, COVID-19 has an asymptomatic course, which contributes greatly to the spread of the disease. While COVID-19 can cause morbidities such as convulsions in the paediatric population, it may also result in mortality in children with underlying serious diseases.
\end{abstract}

Keywords: novel coronavirus, children, COVID-19, symptoms, clinical features

\section{INTRODUCTION}

The SARS-CoV-2 virus causing the novel coronavirus disease (COVID-19) first emerged in the city of Wuhan in Hubei province, China, in December 2019. Following rapid spread of the disease, it was declared a global pandemic by the World Health Organization (WHO) on 11 March 2020 [1]. Similar to SARS infection, COVID-19 creates a life-threatening risk by damaging vital organs such as the lungs, heart, liver and kidneys [2, 3].

Children have been reported to constitute $2.4 \%$ of all the cases in China and $1.7 \%$ in the USA [4, 5]. Despite reports that the disease generally has a milder course in children and mortality is rare, it has been reported that the risk of morbidity and mortality of COVID-19 can be high in children with underlying disorders such as pulmonary dysfunction or immune suppression [6,7]. Previous studies in several countries have reported that healthy children with positive test results for COVID-19 have a mild course of disease and more often play a major role in the spread of the disease as asymptomatic carriers [8-10].
Although there have been several paediatric case reports and case series, the epidemiology and clinical patterns of COVID-19 in paediatric patients have not been clearly revealed [11]. The aim of this study was to contribute to literature by determining the demographic characteristics and clinical findings of symptomatic and asymptomatic paediatric patients with confirmed COVID-19 positivity.

\section{MATERIALS AND METHODS}

\section{Study Design}

This single-center retrospective study was conducted from March 2020 to December 2020 in a tertiary level referral center. Informed consent was obtained from the participants and their parents before examination and the taking of any measurements. The study was approved by the Institutional Review Board and was carried out in accordance with the Declaration of Helsink (Approval date: 09.11.2020, Session no: 91, Decision no:28). Permission for this scientific study was obtained from the Turkish Ministry of Health. 


\section{Participants}

This retrospective study included the information of 130 paediatric patients with COVID-19 confirmed with Rt-PCR test positivity. All data were compiled from the patient's file. Initially, the diagnosis was based on the presence of clinical symptoms and history of exposure to the virus [12-14]. The likelihood of contracting the disease was defined as high, medium, or low risk according to exposure to a COVID-19 case within the past 2 weeks or being in an area where there was an outbreak, being in a community where COVID-19 cases were reported, or new cases of COVID-19 were reported despite living in a non-epidemic area. A child at high risk was evaluated as a suspicious case if they met 2 of the following criteria: (1) high fever, respiratory system symptoms, gastrointestinal symptoms (nausea, vomiting, diarrhea) or fatigue, (2) normal or reduced lymphocyte count in the white blood cell count, or increased C-reactive protein level in the laboratory tests, (3) abnormal chest radiography. For children at moderate and low risk, similar diagnostic criteria were applied after excluding influenza and other common respiratory tract infections. Cases were evaluated as suspicious if they met any one of the following criteria: nasal and pharyngeal smear samples or blood samples tested positive for 2019-nCoV nucleic acid using the Rt-PCR test.

\section{Laboratory Tests and Physical Examination}

A body temperature was measured by means of digital thermometers. Patients with $>38.0^{\circ} \mathrm{C}$ body temperatur was defined as the existence of high fever. A blood sample of $2 \mathrm{ml}$ was taken from all the cases included in the study during first presentation at the hospital before any treatment was started in order to test full blood count (FBC). That was analyzed from the obtained samples with an automatic blood count device (Abbott Celldyn 3500, IL, USA). A venous blood sample of $2 \mathrm{cc}$ was taken for determination of C-reactive protein (CRP) levels using a spectrophotometric chemical analysis device (Architect C16000, Abbott Diagnostics, Abbott Park, IL, USA).

The inclusion criteria includes; the patients $<18$ years old with RT-PCR-confirmed COVID-19 infection. The Exclusion criteria were; if they were aged $>18$ years or had a negative RTPCR test result despite a history of contact and/or clinical suspicion of COVID-19.

\section{STATISTICAL ANALYSIS}

The NCSS (Number Cruncher Statistical System) Statistical Software (Utah, USA) system was used for statistical analysis. Descriptive statistics were stated as mean \pm standard deviation (SD) and median values, number ( $\mathrm{n}$ ) and percentage (\%). The conformity of the data to normal distribution was assessed using the Shapiro-Wilk test and box-plot graphs. In comparisons between groups of variables with normal distribution, the Student's t-test was used, and for those not showing normal distribution, the Mann Whitney U-test was applied. The Pearson Chi-square test was used in the comparisons of qualitative data. A value of $p<0.05$ was considered statistically significant.
Table 1. Demographic characteristics of the cases

\begin{tabular}{cc}
\hline Gender M/F, $\mathrm{n}(\%)$ & $69(53.1 \%) / 61(46.9 \%)$ \\
\hline Age (years), mean \pm SD & $8.53 \pm 5.49$ \\
\hline Age groups & \\
$<1$ year & $11(8.5 \%)$ \\
$1-5$ years & $31(23.8 \%)$ \\
$>5$ years & $88(67.7 \%)$ \\
\hline
\end{tabular}

SD: Standard deviation

Table 2. Clinical findings of the cases

\begin{tabular}{cc}
\hline Symptoms, present/absent, $\mathrm{n}(\%)$ & $59(45.4) / 71(54.6)$ \\
\hline Fever, present/absent, $\mathrm{n}(\%)$ & $40(30.8) / 90(69.2)$ \\
\hline Cough, present/absent, $\mathrm{n}(\%)$ & $14(10.8) / 116(89.2)$ \\
\hline Respiratory problems, present/absent, $\mathrm{n}(\%)$ & $12(9.2) / 118(90.8)$ \\
\hline Abdominal pain, present/absent, $\mathrm{n}(\%)$ & $8(6.2) / 122(93.8)$ \\
\hline Diarrhea, present/absent, $\mathrm{n}(\%)$ & $8(6.2) / 122(93.8)$ \\
\hline Vomiting, present/absent, $\mathrm{n}(\%)$ & $3(2.3) / 123(97.7)$ \\
\hline Joint pain, present/absent, $\mathrm{n}(\%)$ & $3(2.3) / 123(97.7)$ \\
\hline Listlessness, present/absent, $\mathrm{n}(\%)$ & $33(25.4) / 97(74.6)$ \\
\hline Convulsion, present/absent, $\mathrm{n}(\%)$ & $2(1.5) / 124(98.5)$ \\
\hline
\end{tabular}

\section{RESULTS}

The age and gender distributions of the 130 paitents are shown in Table 1.

In all of the cases, $45.4 \%$ of patients were symptomatic and those of includes 34 (57.6\%) males and 25 (42.4\%) females. On the other hand, $54 \%$ of patients had an asymptomatic course and those consist 35 (49.3\%) males and 36 (50.7\%) females. There is no significant different in terms of gender predilection between two groups $(p=0.343)$. The median age were 8 years (range, 0-17 years) in the symptomatic patients and 9 years (range, 0-17 years) in the asymptomatic group. No significant difference was founded in terms of age between two groups $(p=0.892)$.

In the exam, the high fever was determined in $30 \%$ of cases. In addition, the incidence of different clinical findings and complaints were $10.8 \%$ cough, $9.2 \%$ respiratory problems $\%$, $6.2 \%$ diarrhea, $6.2 \%$ abdominal pain, $2.3 \%$ vomiting, $2.3 \%$ joint pain and $1.5 \%$ convulsions (Table 2 ).

In the two cases that developed convulsions, there was no history of convulsions. Both cases were male, aged 3 and 4 years, and both of them experienced bilateral body spasms and mouth deviation lasting approximately 1 minute, without loss of consciousness.

Seven patients (5.4\%) were followed up in the Intensive Care Unit (ICU) and $94.6 \%$ of patients did not require the follow up in ICU. In 7 patients who required intensive care, 2 patients had cerebral palsy, 1 patient had hydrocephaly+shunt replacement, 1 patient had metabolic disease (propionic acidemia), 2 patients had a history of trauma (struck by a motor vehicle), and in 1 patients who had no comorbidity. Mortality developed in 6 of the 7 patients in ICU, all of whom had severe pneumonia with the additional comorbidities stated above.

\section{DISCUSSION}

The results of this study showed that a significant proportion of children with COVID-19 had an asymptomatic course and may play an important role in the spread of the 
disease. Although this study has been shown that COVID-19 may cause convulsions unlike clinical findings such as fever, cough, respiratory distress, abdominal pain, diarrhea, and vomiting.

In the current study, $8.5 \%$ of the cases were under one year and the ages of $23.8 \%$ patients ranging from 1 to 5 years. Consistent with previous findings in literature, $54.6 \%$ of the cases were asymptomatic and only $5.4 \%$ of the cases required intensive care unit follow up. In a study by Bialek et al. [15] analysed of 2572 paediatric cases of COVID-19 confirmed with laboratory tests, the hospital admission rate varied between $6 \%$ and $20 \%$, and $0.58 \%-2.0 \%$ of patients were admitted to ICU. In the same study, it was reported that the highest hospital admission rate of paediatric patients with COVID-19 was children under the age of one year (15\% - 62\%). In 59 children aged $<1$ year requiring hospital treatment, 5 of them were followed up in ICU, and the hospital admission rate of children aged between 1-17 years was reported to be lower (estimated range: $4.1 \%-14 \%)$. In another study of by Tezer et al. [16], the disease course was reported to be mild in $50.4 \%$ of cases, and severe in $0.8 \%$ of cases. The admission rate into ICU was reported for $4.27 \%$ of the cases, and of these $80 \%$ were $<1$ year of age. Similarly, in a study by Lu X et al. [16] of 171 children determined with COVID-19 infection in Wuhan Children's Hosptial, $35.1 \%$ were determined to be asymptomatic or have a mild disease course, and $41.5 \%$ of these were aged $<5$ years.

Fever and cough are the most common symptoms caused by COVID-19 infection [15]. In the current study, the most common symptom was determined to be fever $(30.8 \%)$, followed by cough at the rate of $10.8 \%$, respiratory problems at $9.2 \%$, abdominal pain at $6.2 \%$, diarrhea at $6.2 \%$, vomiting at $2.3 \%$ and convulsions at $1.5 \%$. In a study of 291 children by Bialek et al. [15], fever was determined in 56\%, cough in 54\%, shortness of breath in $13 \%$, and $73 \%$ of the children had at least one symptom. Lu X et al. [17], reported that of 171 children with COVID-19 infection, fever was determined at the rate of $41.5 \%$. The rate of other common symptoms were reported to be cough in $48.5 \%$, pharyngeal erythema in $46.2 \%$, and less commonly, fatigue, rhinorrhea/nasal obstruction, diarrhea and vomiting at rates ranging between $5 \%$ and $9 \%$.

Convulsions have been also reported in COVID-19 patients [18-20]. In the current study, convulsions developed in only 2 cases. One of these had convulsion two times without accompanying high fever. The other case went through the convulsions 3 times, and the body temperature was $38.1^{\circ} \mathrm{C}$. In both cases, bilateral body spasms lasting approximately one minute, with mouth deviation and no loss of consciousness were reported. In the study by Lu L. et al. [21], COVID-19 was reported to be a potential risk factor for convulsions, particularly in acute symptomatic convulsions. Garazzino S et al. [22], reported that seizures in 5 children with COVID-19 infection. Of these 5 cases, 3 had a known history of epilepsy, one had a history of febrile seizure and one experienced a seizure for the first time during COVID-19 infection. As coronaviruses have neuroinvasion and neurotropism characteristics, it should be known that seizures may develop in COVID-19 patients [23]. Paediatric COVID-19 cases with an underlying serious additional pathology are at higher risk of a severe disease course and mortality [24]. In the current study, $5.4 \%$ cases diagnosed with COVID-19 required the monitorization in ICU. In 4 of these cases who developed mortality had a comorbidity as cerebral palsy in 2 patients, hydrocephaly+shunt in 1 patient and metabolic disease (propionic acidemia) in 1 patient and all of patients had concurrent pneumonia. Lu X et al. [17], reported that in 28 $(77 \%)$ of the hospitalized patients, there was one or more underlying medical disease, and in 3 patients who required ICU and invasive mechanical ventilation, all had an additional disease. In studies by Chen $\mathrm{N}$ et al. (25] and Huang $\mathrm{C}$ et al. [11], pneumonia developing associated with COVID-19 was reported to be related to high mortality rates.

This study had a few limitations. First, that the small sample size of the study prohibited generalization of these results for pediatric patients with COVID-19. Second, the retrospective design of the study limited the quality of the data. Finally, the study had been concucted in single-center, however multi-center studies are needed to confirm these results.

\section{CONCLUSION}

In a significant proportion of children, COVID-19 infection has an asymptomatic course, which contributes greatly to the spread of the disease. While COVID-19 causes morbidity such as convulsions in the paediatrc population, the disease had a more severe course in children with an underlying serious disease and may even result in death.

Author contributions: Concept-HG; Design-YO; Supervision-AD; Resource-HG; Materials-HG; Data Collection and/or Processing-AG; Analysis and/or Interpretation-HK; Literature Search-HG; Writing-HG; Critical Reviews-YO.

Funding: No financial or nonfinancial benefits have been received or will be received from any party related directly or indirectly to the subject of this article.

Acknowledgement: The authors would like to thank all staff in the Department of Child Health and Diseases for their valuable contributions.

Declaration of interest: No conflict of interest was declared by the authors.

Ethical approval: This study conformed to the principles of the 2008 Declaration of Helsinki and was approved by the local ethics committee of Harran University, Medical Faculty, Turkey (Approval date: 09.011.2020, Session no: 91, Decision no:28).

\section{REFERENCES}

1. Johns Hopkins University Center for Systems Science and Engineering. Coronavirus COVID-19 globalcases.

2. Chao JY, Derespina KR, Herold BC, Goldman DL, Aldrich M, Weingarten J, et al. Clinical characteristics and outcomes of hospitalized and critically ill children and adolescents with coronavirus disease 2019 at a tertiary care medical center in New York City. J Pediatr. 2020;223:14-9. https://doi.org/10.1016/j.jpeds.2020.05.006 PMid:32407719 PMCid:PMC7212947

3. Lee PI, Hu YL, Chen PY, Huang YC, Hsueh PR. Are children less susceptible to COVID-19? J Microbiol Immunol Infect. 2020;53(3):371-2. https://doi.org/10.1016/j.jmii.2020.02. 011 PMid:32147409 PMCid:PMC7102573

4. CDC COVID-19 Response Team. Coronavirus Disease 2019 in Children - United States, February 12-April 2, 2020. MMWR Morb Mortal Wkly Rep. 2020;69:422-6. https://doi.org/10.15585/mmwr.mm6914e4 PMid:32271728 PMCid:PMC7147903 
5. She J, Liu L, Liu W. COVID-19 epidemic: Disease characteristics in children. J Med Virol. 2020;92(7):747-54. https://doi.org/10.1002/jmv.25807 PMid:32232980 PMCid: PMC7228385

6. Pou C, Nkulikiyimfura D, Henckel E, Olin A, Lakshmikanth T, Mikes J, et al. The repertoire of maternal anti-viral antibodies in human newborns. Nat Med. 2019;25(4):591-6. https://doi.org/10.1038/s41591-019-0392-8 PMid:30886409

7. Nickbakhsh S, Mair C, Matthews L, Reeve R, Johnson PCD, Thorburn $F$, et al. Virus-virus interactions impact the population dynamics of influenza and the common cold. Proc Natl Acad Sci U S A. 2019;116(52):27142-50. https://doi.org/10.1073/pnas.1911083116 PMid:31843887 PMCid:PMC6936719

8. Gumus H, Demir A, Yükkaldıran A. Is mean platelet volume a predictive marker for the diagnosis of COVID-19 in children? Int J Clin Pract. 2020 Dec 5:e13892. https://doi.org/10.22541/au.159708697.70680949

9. Qiu H, Wu, J, Hong L, Luo Y, Song Q, Chen D. Clinical and epidemiological features of 36 children with coronavirus disease 2019 (COVID-19) in Zhejiang, China: an observational cohort study. The Lancet Infectious Diseases. 2020. https://doi.org/10.1016/S1473-3099(20)30198-5

10. Senyuva I, Baysal B. Pregnant and Newborn Health in COVID-19 pandemic: Knowledge level, Attitudre and Perspective of Obstetetricians \& Gynecologist and Pediatricians in Turkey (A Survey-based Study). Electronic Journal of General Medicine. 2021;18(3): em287. https://doi.org/10.29333/ejgm/10831

11. Huang C, Wang Y, Li X, Ren L, Zhao J. Clinical features of patients infected with 2019 novel coronavirus in Wuhan, China. The Lancet. 2020;395:497-506. https://doi.org/ 10.1016/S0140-6736(20)30183-5

12. Fang F, Zhao D, Chen Y, Yang W, Cao Q, Qin LE, et al. Clinical characteristics and imaging manifestations of the 2019 novel coronavirus disease (COVID-19): a multi-center study in Wenzhou city, Zhejiang, China. Journal of Infection. 2020;80(4):388-93. https://doi.org/10.1016/j.jinf.2020.02. 016 PMid:32112884 PMCid:PMC7102539

13. Shen KL, Yang YH, Jiang RM, Wang TY, Zhao DC, Jiang Y, et al. Updated diagnosis, treatment and prevention of COVID19 in children: experts' consensus statement (condensed version of the second edition). World Journal of Pediatrics, 2020;16(3):232-9. https://doi.org/10.1007/s12519-02000362-4 PMid:32333248 PMCid:PMC7180653

14. Loffredo L, Pacella F, Pacella E, Tiscione G, Oliva A, Violi F. Conjunctivitis and COVID-19: A meta-analysis. J Med Virol. 2020;92(9):1413-4. https://doi.org/10.1002/jmv.25938 PMid:32330304 PMCid:PMC7264785

15. Bialek S, Boundy E, Bowen V, Chow N, Cohn A, Dowling N, et al. CDC COVID-19 Response Team. Coronavirus Disease 2019 in Children - United States, February 12-April 2, 2020. MMWR Morb Mortal Wkly Rep. 2020;69(14):422-6. https://doi.org/10.15585/mmwr.mm6914e4 PMid:32271728 PMCid:PMC7147903
16. Tezer H, Bedir Demirdağ T. Novel coronavirus disease (COVID-19) in children. Turk J Med Sci. 2020;50(SI-1):592603. https://doi.org/10.3906/sag-2004-174 PMid:32304191 PMCid:PMC7195991

17. Lu X, Zhang L, Du H, Zhang J, Li YY, Qu J, at al. Chinese Pediatric Novel Coronavirus Study Team. SARS-CoV-2 Infection in Children. N Engl J Med. 2020;382(17):1663-5. https://doi.org/10.1056/NEJMc2005073 PMid:32187458 PMCid:PMC7121177

18. Pinna P, Grewal P, Hall JP, Tavarez T, Dafer RM, Garg R, at al. Neurological manifestations and COVID-19: Experiences from a tertiary care center at the Frontline. J Neurol Sci. 2020;415:116969. https://doi.org/10.1016/j.jns.2020. 116969 PMid:32570113 PMCid:PMC7832569

19. Nalleballe K, Reddy Onteddu S, Sharma R, Dandu V, Brown $A$, Jasti $M$, at al. Spectrum of neuropsychiatric manifestations in COVID-19. Brain Behav Immun. 2020;88:71-4. https://doi.org/10.1016/j.bbi.2020.06.020 PMid:32561222 PMCid:PMC7297688

20. Galanopoulou AS, Ferastraoaru V, Correa DJ, Cherian K, Duberstein S, Gursky J, et al. EEG findings in acutely ill patients investigated for SARS - CoV - 2/COVID - 19: a small case series preliminary report. Epilepsia Open. 2020;5:314-24. https://doi.org/10.1002/epi4.12399

21. Lu L, Xiong W, Liu D, Liu J, Yang D, Li N, et al. New onset acute symptomatic seizure and risk factors in coronavirus disease 2019: A retrospective multicenter study. Epilepsia. 2020;61(6):49-53. PMid:32304092 PMCid:PMC7264627

22. Garazzino S, Montagnani C, Donà D, Meini A, Felici E, Vergine G, et al. Italian SITIP-SIP Pediatric Infection Study Group; Italian SITIP-SIP SARS-CoV-2 paediatric infection study group*. Multicentre Italian study of SARS-CoV-2 infection in children and adolescents, preliminary data as at 10 April 2020. Euro Surveill. 2020;25(18):2000600. https://doi.org/10.2807/1560-7917.ES.2020.25.18.2000600 PMid:32400362 PMCid:PMC7219028

23. Moriguchi T, Harii N, Goto J, Harada D, Sugawara H, Takamino J, et al. A first case of meningitis/encephalitis associated with SARS-Coronavirus-2. Int J Infect Dis. 2020; 94:55-8. https://doi.org/10.1016/j.ijid.2020.03.062 PMid: 32251791 PMCid:PMC7195378

24. Dong Y, Mo X, Hu Y, Qi X, Jiang F, Jiang Z, et al. Epidemiology of COVID-19 among children In China. Pediatrics 2020;145(6):e20200702. https://doi.org/10.1542/peds. 2020-0702 PMid:32179660

25. Zhang $X$, Zhang L. Epidemiological and clinical characteristics of 99 cases of 2019 novel coronavirus pneumonia in Wuhan, China: a descriptive study. Lancet. 2020;395(10223):507-13. https://doi.org/10.1016/S01406736(20)30211-7 